DOI: 10.34185/1991-7848.itmm.2020.01.023

\title{
THE USE OF THE APPARATUS OF ORDINARY DIFFERENTIAL EQUATIONS IN SIMULATION OF ECONOMIC AND ENVIRONMENTAL SYSTEMS
}

\author{
Oliinyk Andrii, Feshanych Lidiia \\ Ivano -Frankivsk National Technical University of Oil and Gas \\ Ukraine, Ivano -Frankivsk
}

\begin{abstract}
The ordinary differential equations techniques applying to investigate the economical and ecological systems has been considered in presented article. The interconnected economical complexes development for the countries with the different economical potential has been simulated. The population economical activity influence on the environment pollution and the state of region's flora has been investigated. The economical efficiency of the new technical diagnostics implementation has been studied. The methods of presented models realization has been presented and investigated, the results of tested calculations have been presented and one's analysis has been given. The directions of future investigations have been determined.
\end{abstract}

Key words: DIFFERENTIAL EQUATION, MATHEMATICAL MODELING METHOD, MODELING, DIAGNOSTICS.

In predicting the development of interconnected economies, the question arises whether economies with relatively low levels of development may not suffer significant economic losses at a time when the world's leading economies are suffering losses as a result of the economic crisis. The methods of mathematical design are used for research of the indicated question with the use of the systems as a "predator-victim" [1], that allows to build mathematical models and define their descriptions that would allow to answer theset questions. The task is reduced to solution Liabilities system of differential equations of the form:

$$
\left\{\begin{array}{l}
\frac{d x_{1}}{d t}=A_{1} x_{1}\left(A_{2}-x_{1}\right)-A_{3} x_{1} x_{2}+A_{4} x_{1} x_{3} \\
\frac{d x_{2}}{d t}=A_{5} x_{2}\left(A_{6}-x_{2}\right)-A_{7} x_{1} x_{2}+A_{8} x_{1} x_{3} \\
\frac{d x_{3}}{d t}=A_{9} x_{3}\left(A_{10}-x_{3}\right)+A_{11} x_{1} x_{3}+A_{4} x_{1} x_{2}
\end{array},\right.
$$


there $x_{1}$ and $x_{2}$ - economically strong countries, $x_{3}$ a country with a low level of economy with appropriate initial conditions $x_{1}(0)=x_{10} ; x_{2}(0)=x_{20} ; x_{3}(0)=x_{30}$. The coefficients $A_{i}$ could be present as a time function $A_{i}=A_{i}(t)$.

Another model is related to a system described by three differential equations for functions: $x(t)$ - population in the region; $y(t)$ - the level of pollution and other non-harmful effects on the environment caused by the economic activity of the population; $z(t)$ - the level of flora of the region, however, the equation system looks like:

$$
\left\{\begin{array}{l}
\frac{d x}{d t}=A x-B y+C z \\
\frac{d y}{d t}=D x-E z \\
\frac{d z}{d t}=H x-G y+F z
\end{array} .\right.
$$

Initial conditions must be specified for the correct formulation of the modeling task:

$$
\left\{\begin{array}{l}
X(0)=X_{0} \\
Y(0)=Y_{0} \\
Z(0)=Z_{0}
\end{array} .\right.
$$

The third model describes a situation for which the functions $x(t), y(t) ; z(t)$ are introduced with the following meaning: $x(t)$ - costs for implementation of new technical diagnostics and control standards; $y(t)$ - costs for elimination of emergencies consequences; $z(t)$ is the efficiency of the studied industrial system's element When a mathematical model is constructed, a differential equation system that describes how to modify the corresponding variables per unit of time in assuming the nature of the relationship between the quantities is recorded. As a result, the following system of ordinary differential equations that binds the variables $x(t) ; y(t) ; z(t)$ is obtained:

$$
\left\{\begin{array}{l}
\frac{d x}{d t}=K_{1} x(A-x)-K_{2} y+K_{3} z \\
\frac{d y}{d t}=K_{4} x(A-x)+K_{5} y(B-y)+K_{6} z \\
\frac{d z}{d t}=K_{7} x-K_{8} y
\end{array}\right.
$$


with appropriate initial conditions.

All models are brought to numerical realization in the form of software complexes by Runge-Kutta methods [2], it allows to carry out a wide class of calculations in order to estimate the dynamics of the process development depending on the suitable coefficients of the model.

In the implementation of model (2) the values of coefficients at which periodic crisis manifestations of countries with higher levels of economic development (series 1, 2 in Figure 1) do not affect the level of economy of a country with relatively weaker economic indicators( row 3 ) were established.

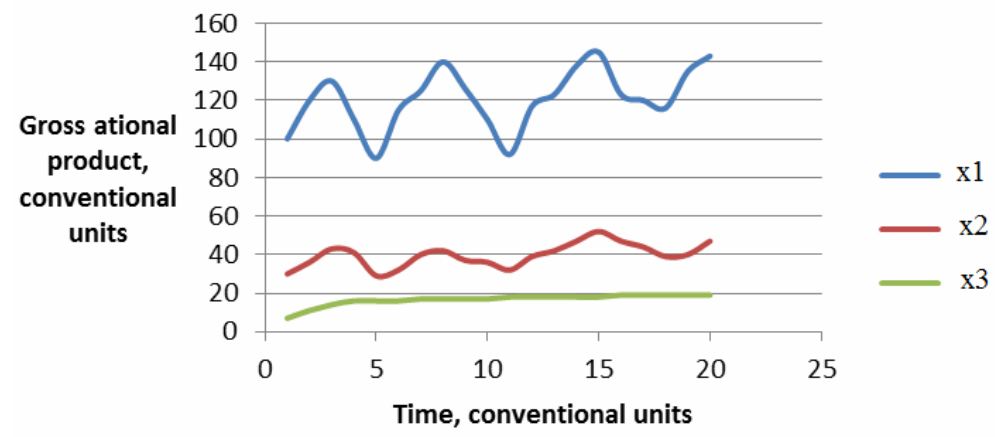

Figure 1 - Countries economics indicators dynamics

Implementation of the model (3), (4) allows you to set these coefficients, in which the stability of solutions with the desired asymptotic values (Figure 2) is provided.

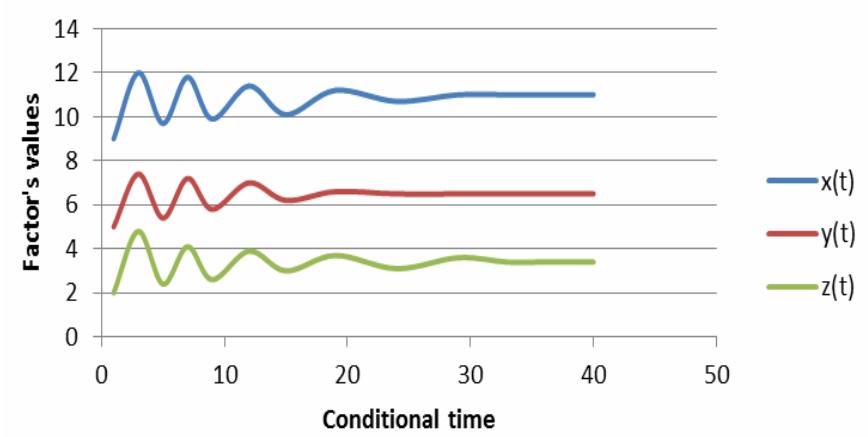

Figure 2 - The change of economic and ecological system indicators dynamics

The implementation of model (5) allows us to set the values of coefficients in which the stability of the solutions with the desired asymptotic values of the indicators and the dynamics of their change over time is ensured (figure 3): 


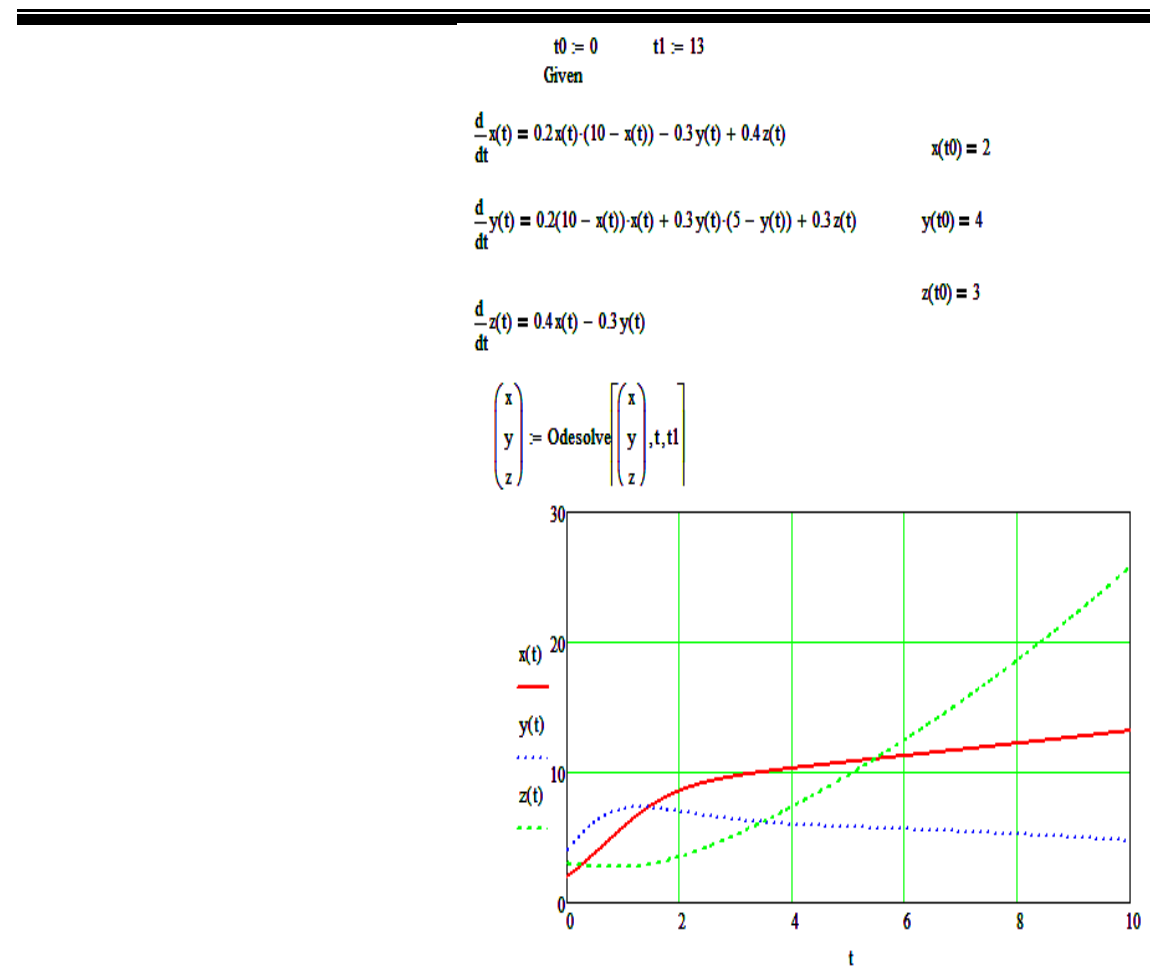

Figure 3 - The change of cost indicators for standards of technical diagnostics implementation, for elimination of emergencies consequences and efficiency of gas transmission system's work

The results of the calculations can determine the time at which the advertising campaign can be rolled - further investment has no proper effect.

Advertising campaign intesity

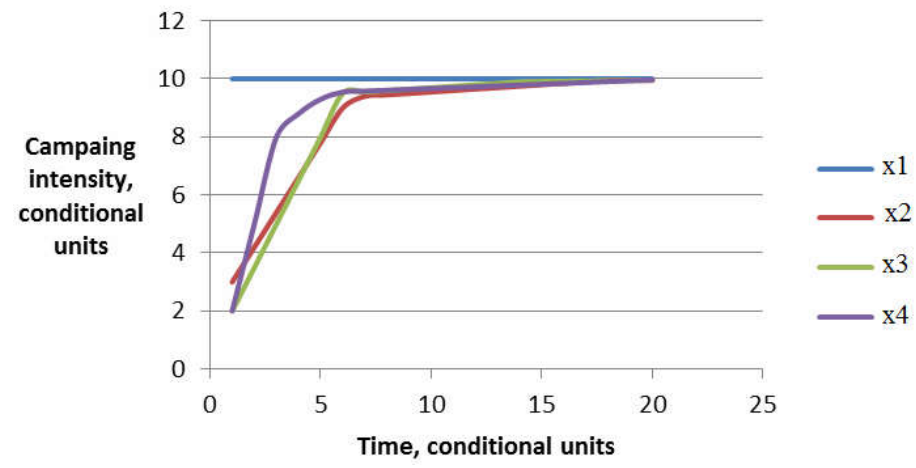

Figure 4 - The results of advertising campaign intensity model calculations

The technique of ordinary differential equations can be successfully applied to the simulation of the interconnected economies development, to estimation the change of economic and ecological system indicators dynamics and the change of cost indicators for standards of technical diagnostics implementation, for elimination of emergencies consequences and efficiency of gas transmission system's work and to predictions the advertising campaign efficiency. All this 
Ministry of Education and Science of Ukraine

The National Metallurgical Academy of Ukraine, Dnipro, 17 - 19 March, 2020

models can be realized using the simple linear and quadratic type relationships, which, however, allow to receive the numerical results that are sufficiently accurate in terms of practical needs.

\section{References}

1. Volterra, V. (1976). Matematicheskaya teoriya borby za suschestvovanie [Mathematical theory of fight for existence]. Moscow - Izhevsk: Institut kompyuternyih issledovaniy, 2004, 24- 158 s. (In Russian).

2.Samarskiy, A. A., Gulin, A.V. (1982). Vvedenie v tsifrovyie metody [Introduction into digital methods]. M.: Nedra. 43-272. (In Russian). 